\title{
Coeliac disease is associated with depression in children and young adults with type 1 diabetes: results from a multicentre diabetes registry
}

\author{
Sascha René Tittel ${ }^{1,2}$ (1) Désirée Dunstheimer ${ }^{3} \cdot$ Dörte Hilgard $^{4} \cdot$ Burkhild Knauth $^{5} \cdot$ Elke Fröhlich-Reiterer $^{6}$. \\ Angela Galler ${ }^{7} \cdot$ Michael Wurm $^{8} \cdot$ Reinhard Walter Holl ${ }^{1,2} \cdot$ For the DPV Initiative
}

Received: 14 October 2020 / Accepted: 28 November 2020 / Published online: 23 January 2021

(c) The Author(s) 2021

\begin{abstract}
Aims To analyse the association between coeliac disease (CD) and depression in children, adolescents, and young adults with type 1 diabetes (T1D).

Methods We included 79,067 T1D patients aged 6-20 years, with at least six months of diabetes duration, and treatment data between 1995 and 2019 were documented in the diabetes patient follow-up registry. We categorized patients into four groups: T1D only $(n=73,699), \mathrm{T} 1+\mathrm{CD}(n=3379)$, T1D + depression $(n=1877)$, or T1D + CD + depression $(n=112)$.

Results CD and depression were significantly associated (adjusted OR: 1.25 [1.03-1.53]). Females were more frequent in both the depression and the $\mathrm{CD}$ group compared with the T1D only group. Insulin pumps were used more frequently in $\mathrm{T} 1 \mathrm{D}+\mathrm{CD}$ and T1D + depression compared with T1D only (both $p<.001)$. HbA1c was higher in T1D + depression $(9.0 \%$ [8.9-9.0]), T1D+CD+ depression (8.9\% [8.6-9.2]), both compared with T1D only (8.2\% [8.2-8.2], all $p<.001)$. We found comorbid autism, attention deficit hyperactivity disorder, anxiety, schizophrenia, and eating disorders more frequently in the T1D + CD + depression group compared with T1D only (all $p<.001$ ).

Conclusions CD and depression are associated in young T1D patients. The double load of T1D and CD may lead to an increased risk for depression. Depression was associated with additional psychological and neurological comorbidities. Aside from imperative CD screening after T1D diagnosis and regular intervals, depression screening might be helpful in routine care, especially in patients with diagnosed CD.
\end{abstract}

Keywords Coeliac disease $\cdot$ Depression $\cdot$ Paediatric $\cdot$ Endocrinology $\cdot$ DPV

\section{Abbreviations \\ CD Coeliac disease \\ DKA Diabetic ketoacidosis \\ DPV Diabetes patient follow-up \\ SDS Standard deviation score \\ T1D Type 1 diabetes}

Managed by Massimo Porta.

Supplementary Information The online version contains supplementary material available at (https://doi.org/10.1007/ s00592-020-01649-8).

Sascha René Tittel

sascha.tittel@uni-ulm.de

Extended author information available on the last page of the article

\section{Introduction}

Coeliac disease (CD) is an autoimmune-mediated disorder resulting in intestinal damage and mucosal atrophy on consumption of gluten [1]. CD is a common comorbidity in type 1 diabetes (T1D) with an average prevalence of approx. $5 \%$ versus $1 \%$ in the general population [2]. In an international comparison of children and adolescents with T1D, $\mathrm{CD}$ prevalence has been reported to range between $1.6 \%$ and $16.4 \%$ [3]. Prevalence of CD is increasing, even in regions like Asia, where gluten is now consumed more frequently due to changes in eating habits and infant feeding [4].

The first description of CD was given by Samuel Gee in 1888 , suggesting dietary treatment; however, wheat, rye, and oats as toxic components were not identified until 1950 [5]. Earlier publications discussing CD and behavioural abnormalities presented case reports of phlegmatic, "difficult," or "naughty" infants and children with overall bad behaviour, 
crying attacks of unknown reasons during the night, low appetite, and general negativity $[6,7]$, which improved after initiation of a gluten-free diet (GFD).

Guidelines by the European Society for the Study of Coeliac Disease recommend duodenal biopsies for $\mathrm{CD}$ diagnosis in adults [8], especially if patients have pre-existing T1D, family history of CD, or other associated comorbidities [9]. CD in adults is often associated with concomitant extra-intestinal symptoms including anxiety, depression, thoughts of selfharm, dementia, epilepsy, attention deficit hyperactivity disorder (ADHD), autism, eating disorders, infertility, and others [10-17].

However, not every patient with CD experiences symptoms [18]. As a genetic component of CD has been recognized, family members of $\mathrm{CD}$ patients are often screened before symptoms occur [19, 20]. The recent ESPGHAN guidelines postulate antibody testing in all suspected CD cases with subsequent biopsy in case the antibody titers are not more than 10 times the upper limit of the reference range [1]. Based on the increased prevalence of $\mathrm{CD}$ in T1D, the ISPAD guidelines also recommend $\mathrm{CD}$ screening at diagnosis of T1D and at 2 and 5 years thereafter [17]. The multinational TEDDY study focused on genetic and environmental risk factors for T1D and CD in newborns and infants that showed typical HLA haplotypes [21].

Until today, the only way to treat $\mathrm{CD}$ and prevent symptoms is via strict GFD, since even the smallest amounts of gluten can cause the onset or aggravation of CD symptoms [12]. By diagnosing $\mathrm{CD}$ and strictly adhering to a GFD, the occurrence of symptoms can be prevented.

According to the World Health Organization (WHO), the global prevalence of depressive disorders in children and adolescents ranges from 3-4.5\% [22]. In young T1D patients, the prevalence of depression ranges from 15 to $30 \%$ [23-25].

The treatment of T1D, CD, and depression all requires different knowledge in the respective treatment and therefore a multidisciplinary team. To our knowledge, there are no studies about the combined occurrence of depression and $\mathrm{CD}$ in paediatric and young adult T1D patients. Our aim is to fill that gap and compare young T1D patients with $\mathrm{CD}$ and/or depression to T1D patients with neither CD nor depression, investigating demographic and therapy-related outcomes. In addition, we assessed possible associations with further psychological, neurological, and microvascular comorbidities.

\section{Materials and methods}

\section{Participants}

We included patients from the diabetes prospective followup registry (DPV) that fulfilled the following criteria: (1)
T1D diabetes onset at age $\geq 6$ months, (2) age 6-20 years, (3) at least 6 months of diabetes duration, and (4) treatment data available between January 1995 and December 2019.

DPV is a multicentre initiative comprising 588,860 diabetes patients (March 2020) and 501 centres in Germany, Austria, Switzerland, and Luxembourg. In total, 476 centres contributed data to this analysis. More than $90 \%$ of paediatric T1D patients in Germany are estimated to be documented in the DPV [2]. Data collection and analysis of anonymized data from the DPV registry were approved by the Medical Faculty Ethics Committee of Ulm University, Germany, and by the local review boards of participating centres. Semiannually, centres send pseudonymized data to Ulm, Germany, where data are validated, anonymized, and added to the cumulative database [2].

We assigned patients to mutually exclusive groups: T1D only, T1D + CD, T1D + depression, or T1D + CD + depression based on all observed data from that patient in the DPV. T1D only was our reference group.

\section{Variables}

CD diagnosis was based on clinical diagnosis (in part based on antibody results) by the treatment centre, with or without confirmation by small bowel biopsy. Depression was defined by clinical diagnosis (ICD10 and DSM-V) or specific pharmacotherapy [26]. Demographic data were age, diabetes duration, age at diabetes diagnosis, sex, and migration background (at least one parent or patient not born in Germany, Austria, Switzerland, or Luxembourg). Outcomes of interest were BMI-SDS, HbA1c, type of insulin therapy (injection vs. pump therapy), severe hypoglycaemia, diabetic ketoacidosis (DKA), and psychological/neurological comorbidities including autism, ADHD, schizophrenia, anxieties, and eating disorders (anorexia, bulimia, binge eating, others). Psychological and neurological comorbidities were documented by appropriate diagnosis terms or ICD10 codes by experienced psychologists that are present in every certified diabetes centres participating in DPV. We also analysed microalbuminuria (defined by urine albumin-to-creatinine ratio $\geq 30 \mathrm{mg} / \mathrm{g}$ ) and retinopathy. Patients with missing information on retinopathy or nephropathy were excluded from the respective analysis only. $\mathrm{HbA} 1 \mathrm{c}$ was standardized to the reference range of $4.05 \%-6.05 \%$ according to the Diabetes Control and Complication Trial (DCCT) using the multiple of the mean method [2]. For BMI-SDS values, we used AGA (German paediatric obesity working group) reference data [27]. We defined severe hypoglycaemia as hypoglycaemic episode with cognitive impairment (with or without coma) necessitating help from another person [2]. DKA was defined as $\mathrm{pH}<7.3$ and/or serum bicarbonate $<15 \mathrm{mmol} / \mathrm{l}$. 


\section{Data aggregation}

We aggregated data as medians for all records during the most recent treatment year of each patient. Depression, $\mathrm{CD}$, and psychological comorbidities were aggregated per lifetime.

\section{Statistical methods}

In the unadjusted analysis of demographic and clinical variables (Table 1), medians and interquartile ranges (IQR) are presented for continuous variables and percentages for categorical variables. We used Wilcoxon's rank-sum test for unadjusted group comparisons of continuous variables and $\chi^{2}$-test for categorical variables. Two-sided $\mathrm{p}$-values were adjusted for multiple testing according to Bonferroni-Holm, and significance was set at $<0.05$. For HbA1c and BMISDS, we used linear regression models and reported outcomes as adjusted least-square means [95\% confidence interval (CI)], and logistic models for the association of CD with depression (odds ratio with 95\% CI), and the frequency of other comorbidities (least-square mean with $95 \% \mathrm{CI}$ ). Severe hypoglycaemia or DKA rates per patient-year (least-square mean with 95\% CI) were calculated using negative binomial regression models with individual time under risk as offset.
All regression models were adjusted for sex, age group, age at diabetes onset group, and migration background. Age was categorized as $6-12,>12-18,>18-20$ years and age at diabetes onset as $\leq />10$ years. For sensitivity analysis, we adjusted the microalbuminuria and retinopathy models additionally for HbA1c groups $(\leq />7.5 \%(58.5 \mathrm{mmol} / \mathrm{mol}))$.

\section{Results}

Among 79,067 T1D patients, 1,877 (2.4\%) had comorbid depression, 3,379 (4.3\%) had CD (62.2\% biopsy-proven), and $112(0.1 \%)$ patients had CD and depression (65.2\% biopsy-proven). T1D only was found in 73,699 (93.2\%). We found a significant association between $\mathrm{CD}$ and depression (adjusted OR: 1.25 [1.03-1.53]). For sensitivity analysis, we calculated the same model with biopsy-proven $\mathrm{CD}$ only, where the association was not significant (OR: 1.26 [0.99-1.60]).

Patients with T1D + CD were younger, and patients with T1D + depression (with or without additional CD) were older compared to the reference group (all $p<0.001$, Table 1). We found an imbalance regarding sex distribution in all comorbidity groups. (Females were more common in the three $\mathrm{CD} /$ depression groups compared with the reference

Table 1 Characteristics of T1D patients during most recent treatment year

\begin{tabular}{|c|c|c|c|c|c|c|c|c|}
\hline & Total & $\mathrm{T} 1 \mathrm{D}+\mathrm{CD}+\mathrm{D}$ & $\mathrm{T} 1 \mathrm{D}+\mathrm{CD}$ & $\mathrm{T} 1 \mathrm{D}+\mathrm{D}$ & T1D only & $\begin{array}{l}p \text {-value T1D } \\
\text { only versus } \\
\text { T1D + CD +D }\end{array}$ & $\begin{array}{l}p \text {-value T1D } \\
\text { only versus } \\
\mathrm{T} 1 \mathrm{D}+\mathrm{CD}\end{array}$ & $\begin{array}{l}p \text {-value T1D } \\
\text { only versus } \\
\text { T1D+D }\end{array}$ \\
\hline $\begin{array}{l}\text { Number of } \\
\text { cases }\end{array}$ & 79,067 & 112 & 3379 & 1877 & 73,699 & & & \\
\hline Male sex [\%] & 52.8 & 34.8 & 44.3 & 42.7 & 53.5 & $<.001$ & $<.001$ & $<.001$ \\
\hline Age [y] & $\begin{array}{c}16.5[13.3- \\
17.8]\end{array}$ & $\begin{array}{l}17.3[15.6- \\
18.9]\end{array}$ & $\begin{array}{l}15.6[11.9- \\
17.6]\end{array}$ & $\begin{array}{c}17.4[16.1- \\
18.5]\end{array}$ & $\begin{array}{c}16.5[13.3- \\
17.8]\end{array}$ & $<.001$ & $<.001$ & $<.001$ \\
\hline $\begin{array}{l}\text { Diabetes dura- } \\
\text { tion }[y]\end{array}$ & $6.0[3.2-9.4]$ & $8.9[5.5-12.4]$ & 7.3 [4.3-11.2] & $6.8[4.1-10.4]$ & $5.9[3.1-9.3]$ & & & \\
\hline $\begin{array}{l}\text { Age at diabe- } \\
\text { tes diagnosis } \\
{[y]}\end{array}$ & $8.9[5.5-12.1]$ & 7.7 [4.0-11.4] & 6.2 [3.4-9.8] & $\begin{array}{l}10.1 \\
{[6.7-12.7]}\end{array}$ & $9.0[5.6-12.1]$ & .11 & $<.001$ & $<.001$ \\
\hline $\begin{array}{l}\text { Pump therapy } \\
\text { [\%] }\end{array}$ & 39.1 & 48.6 & 53.3 & 42.7 & 38.3 & .11 & $<.001$ & $<.001$ \\
\hline $\begin{array}{l}\text { Severe hypo- } \\
\text { glycaemia } \\
{[\%]}\end{array}$ & 7.2 & 8.0 & 5.7 & 9.1 & 7.2 & .73 & $<.01$ & $<.01$ \\
\hline $\begin{array}{l}\text { Diabetic } \\
\text { ketoacidosis } \\
{[\%]}\end{array}$ & 2.4 & 6.3 & 1.8 & 6.5 & 2.3 & .03 & .07 & $<.001$ \\
\hline $\begin{array}{l}\text { Migration } \\
\text { background } \\
{[\%]}\end{array}$ & 17.4 & 24.1 & 18.9 & 17.8 & 17.3 & .12 & .03 & .60 \\
\hline
\end{tabular}

Data are presented as median [interquartile range] or as percentage

$p$-values were adjusted for multiple testing

$C D$ Coeliac disease, $D$ depression, $T 1 D$ type 1 diabetes 
group (all $p<0.001)$.) There were no significant differences in the proportions of patients with migration background between the groups, except in T1D + CD compared with T1D only ( $18.9 \%$ vs. $17.3 \%, p=0.03)$. Pump usage was more frequent in T1D + CD and in T1D + depression patients (both $p<0.001$ ) compared with the reference group (Table 1).

T1D + CD patients had a lower adjusted BMI-SDS $(0.36$ [0.33-0.40]) compared with T1D only $(0.52$ [0.51-0.53]) and T1D+depression patients $(0.55$ [0.51-0.60], all $p<0.001)$. There was no difference between T1D $+\mathrm{CD}$ and $\mathrm{T} 1 \mathrm{D}+\mathrm{CD}+$ depression in BMI-SDS. T1D + depression with or without $\mathrm{CD}$ was associated with worse metabolic control compared with T1D only (both $p<0.001$, Fig. 1). We found higher rates of DKA in T1D + depression patients compared to the reference group and higher rates of severe

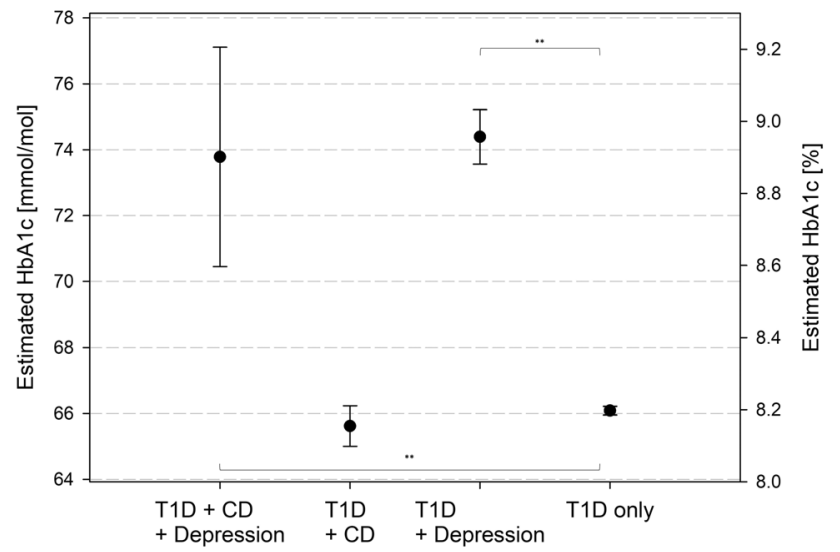

Fig. 1 Estimated HbA1c adjusted for age, age at diabetes onset, sex, migration background, treatment year. T1D: type 1 diabetes; CD: coeliac disease. $p$-values: $* *<.00195 \%$ confidence intervals

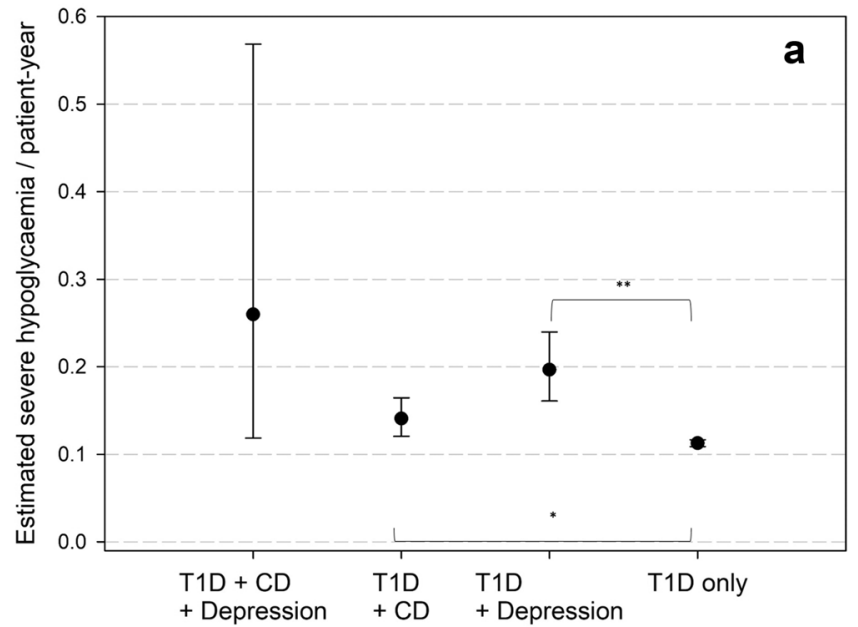

hypoglycaemia in T1D + depression and T1D + CD compared with the reference group (Fig. 2).

Microalbuminuria was more frequent in patients with $\mathrm{T} 1 \mathrm{D}+\mathrm{CD}+$ depression (Fig. 3a). Adjusting for HbA1c did not have an impact on this result. Retinopathy occurred more often in T1D+depression compared with the reference group, even after HbA1c adjustment (Fig. 3b). In patients with T1D+depression with or without $\mathrm{CD}$, we found higher rates of autism or ADHD (Fig. 3c, d), as well as anxiety, schizophrenia, or eating disorders (Fig. 3e, f, g) compared with the reference group.

\section{Discussion}

We found a positive association between $\mathrm{CD}$ and depression among children and young adults with T1D. In the general population, $\mathrm{CD}$ is associated with psychological disorders, such as depression [12], with a lifetime prevalence of up to $31 \%$ in CD patients compared with $7 \%$ of patients without CD [28]. Our study confirms this association for usually asymptomatic $\mathrm{CD}$ in patients with T1D. Causes might include excessive cytokine secretion, or iron deficiency from malabsorption, reducing dopamine levels [12, 29, 30]. Early detection of CD is important, since adhering to a GFD may alleviate depressive symptoms [12, 31, 32]. Having T1D and additional $\mathrm{CD}$ is a heavier burden than having only one chronic disease. If we assume that depression develops later than $\mathrm{CD}$, it is not surprising that the double load may lead to an increased risk for depression. However, we cannot say whether the increased risk for depression in $\mathrm{CD}$ is due to a restricted diet or due to untreated $\mathrm{CD}$.

In particular, young patients with CD without T1D may experience exclusion from everyday life or bullying due to

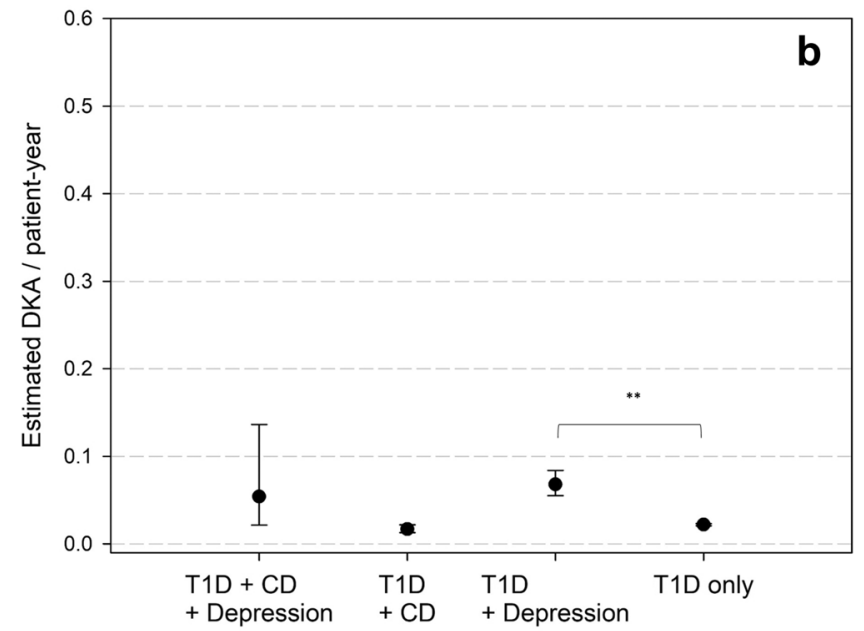

Fig. 2 Estimated event rates for glycaemic decompensation adjusted for age, age at diabetes onset, sex, migration background, treatment year. T1D: type 1 diabetes; CD: coeliac disease. a: severe hypoglycaemia, b: diabetic ketoacidosis (DKA). $p$-values: $*<.05 ; * *<.001$ 
being different or the special diet they have to adhere to $[33,34]$. Psychosocial distress may also derive from costs or availability of gluten-free food [35]. Since lifelong adherence to a GFD is a difficult task, it is to argue whether adhering to a strict diet in patients with only light symptoms and positive $\mathrm{CD}$ antibodies is preferable, or whether this has negative psychological effects. There exist conflicting data on a possible benefit of GFD in patients with only light or no symptoms [36, 37]. While there are reports of improved quality of life after GFD initiation, some report negative feelings in patients with GFD and reduced pleasure concerning meals, and even higher rates of depression [12, 38].

Eating disorders have a known association with T1D as well as with CD and depression [12, 39]. Comorbid eating disorders or incomplete adherence to a GFD may lead to a lower BMI in CD due to malabsorption. It is difficult to objectively assess adherence to a GFD; however, constantly positive anti-transglutaminase antibodies are indicative. Our CD patients had a lower BMI-SDS compared with the T1D only group, which is in line with previous reports [2]. Eating disorders, however, were not more frequently observed in CD patients in our data. In contrast, patients with $\mathrm{CD}$ are reported to have a higher BMI due to potentially higher fat and caloric uptake [40] or due to adolescents possibly choosing quickly available gluten-free snacks instead of healthy alternatives [41].

The lower BMI-SDS in T1D + CD patients (without depression) could also hint at healthier eating habits, although glycaemic control was not significantly better compared with the T1D only group. Patients with T1D+depression (with or without $\mathrm{CD}$ ), on the other hand, had worse glycaemic control compared with T1D only, also resulting in higher rates of severe hypoglycaemia and DKA for patients with T1D+depression. Depression in T1D is known to affect adherence to insulin treatment, leading to worse metabolic outcome, higher rates of glycaemic decompensation, and more hospital admissions [24]. ISPAD guidelines also suggest investigating possible eating disorders in T1D patients with worse metabolic control and a multidisciplinary team with a specialist paediatric dietician [3].

Higher frequencies of anxiety and/or depression in adolescent T1D patients are well established. In our study, depression was diagnosed overall in only $2.5 \%$, which is far less than the previously reported $12-30 \%$ of adolescents and young adults [23, 25, 42]. Therefore, one might conclude that depression is less frequent in younger T1D patients, which we included in this study. On the other hand, routine depression screening in diabetes centres is not (yet) established and patients with depression might be missed if only clinically diagnosed patients are recorded. This could be a reason for the lower frequency of depression in our cohort.

Patients with depression were older compared with the reference group. Depression might require a certain stage of mental development to occur or to allow diagnosis, as diagnosing depression in young children is difficult [43]. As reported before, $\mathrm{CD}$ patients were younger compared with the reference group, implying a greater risk of $C D$ in patients with earlier T1D onset [2]. Early screening for CD and depression in T1D patients may help improve quality of life and prevent consequences of undetected comorbidity.

As stated earlier, CD has been reported to be associated with a number of neurological and psychiatric comorbidities such as ADHD, autism, anxiety, and schizophrenia [12]. Interestingly, in our cohort none of these comorbidities were significantly more frequent in $\mathrm{CD}$ patients compared with the T1D only group. However, all of these were significantly more frequent in patients with depression (with or without additional CD). Depression is known to be associated with other psychiatric comorbidities and even with conditions such as autism [44].

In our registry, $\mathrm{CD}$ was diagnosed in $4.4 \%$ of patients, either via biopsy or via clinical diagnosis, which is in line with previous reports $[2,45] .62 .2 \%$ of our CD patients had biopsy-proven $\mathrm{CD}$. According to several guidelines $[1,17]$, among other autoimmune diseases, paediatric patients with T1D are recommended to be screened for CD autoantibodies, since links between T1D and CD are well known [2] and attributed to their common HLA haplotype DR3-DQ2 or DR4-DQ8 [46]. Until recently, guidelines recommended duodenal biopsies at multiple sites to confirm CD in asymptomatic patients $[8,17]$.

There is still no definitive statement on whether there is an association between sex and CD [2]. However, female sex is widely known to be associated with autoimmune diseases in general, though for yet unknown reasons [47]. Our findings imply an association of female sex and both $\mathrm{CD}$ and depression. Charles et al. suggested a 2:1 ratio of females to males concerning mental health disorders [43], which is similar in our patients with $\mathrm{CD}$ and depression (65.2\% female). Therefore, we suggest that especially female patients should be screened for $\mathrm{CD}$ or signs of depression.

Major strengths of this study include the big sample size of paediatric T1D patients from different European countries and the representative nature of the DPV registry for young T1D patients in Germany, Austria, and Luxemburg. One weakness that is inherent to the investigated question is the dependence on observational studies; therefore, causality between $\mathrm{CD}$ and depression cannot be proved. We are also unable to make statements about the prevalence of depression and $\mathrm{CD}$ in the registered patients due to possible underreporting. Validated questionnaires on depression such as the PHQ-9 were not available for our analysis. We do not have information on adherence to a GFD, so we could not analyse possible differences in outcomes between patients adhering to a GFD and patients that did not. Since ethnicity is not a suitable concept in 

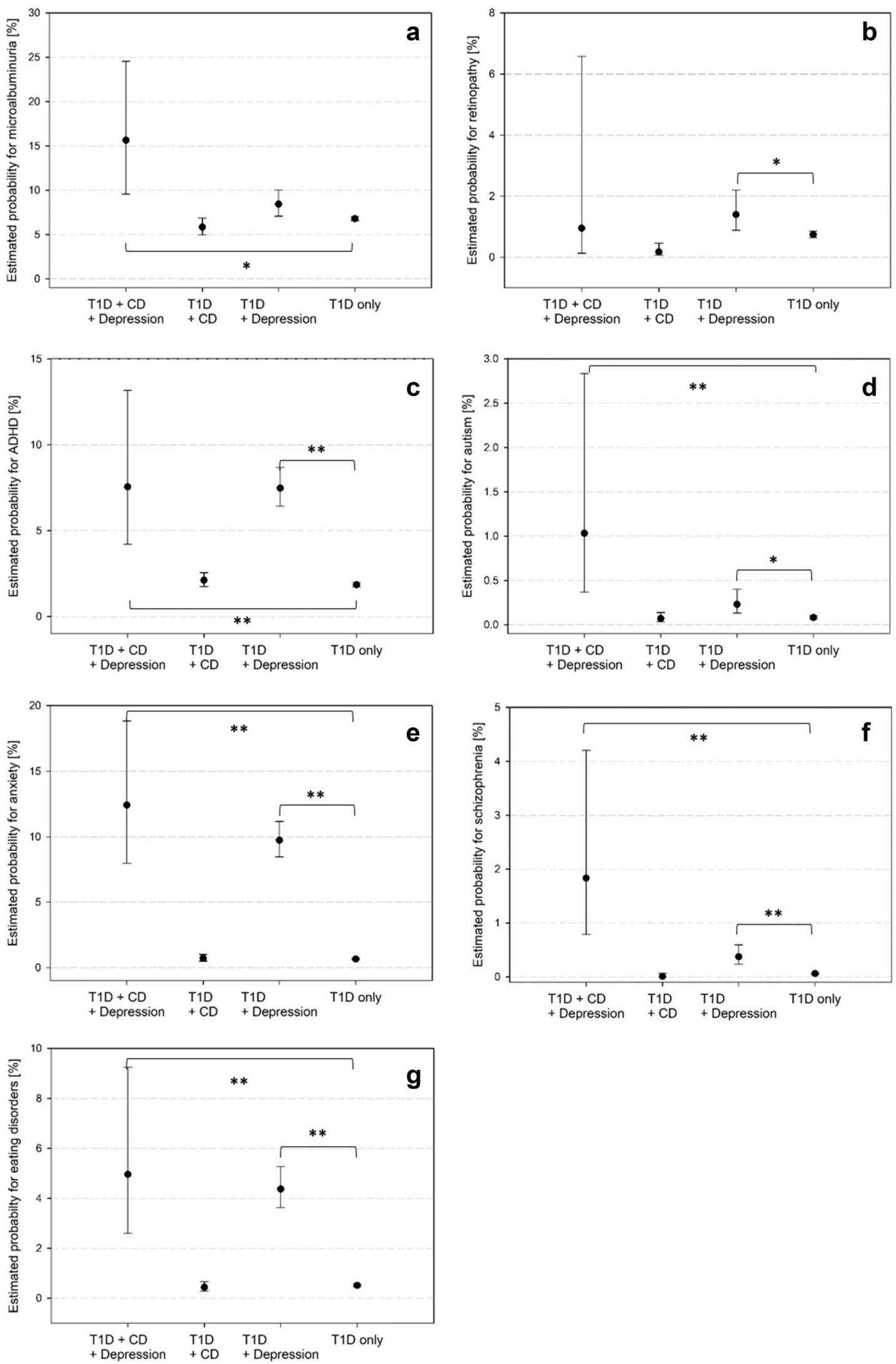
4Fig. 3 Probabilities for comorbidities were calculated via logistic regression and adjusted for age, age at diabetes onset, sex, migration background, treatment year. T1D: type 1 diabetes; CD: coeliac disease. a: Microalbuminuria, b: Retinopathy, c: ADHD, d: Autism, e: Anxiety disorders, f: Schizophrenia, g: Eating disorders. $p$-values: $*<.05 ; * *<.001$

Germany, we used migration background as a covariate instead. Finally, since DPV is a diabetes registry we do not have data on patients with CD but without T1D to analyse the incidence of depression in CD patients compared to healthy controls. However, a recent study found an anxiety prevalence of $62.7 \%$ and depression prevalence of $34.9 \%$ in CD patients [48].

\section{Conclusion}

Depression is disproportionately more frequent in young T1D patients with additional CD. Aside from the recommended CD screening at T1D diagnosis and in regular intervals thereafter, as suggested by several guidelines, depression screening can be helpful in routine care, especially in patients with diagnosed CD. Interdisciplinary cooperation between diabetologists, psychologists, and gastroenterologists should be promoted.

Acknowledgements Special thanks to A. Hungele and R. Ranz for the development of the DPV documentation software and K. Fink and E. Bollow for the DPV data management (clinical data managers, Ulm University). We also thank Stefanie Lanzinger, $\mathrm{PhD}$, for revising the manuscript. We further wish to thank all centres contributing to this analysis (see Supplement). This work was supported by the German Centre of Diabetes Research (DZD) funded by the Federal Ministry of Education and Research (FKZ 82DZD14A02). The German Diabetes Association (DDG) and the Robert Koch Institute (RKI) provided further financial support for the DPV registry.

Author contributions All authors have read and approved the final manuscript. SRT performed the analysis, wrote, and edited the manuscript. DD, DH, BK, EF-R, AG, and MW contributed data, and reviewed and edited the manuscript. RWH conceptualized the study, and reviewed and edited the manuscript. RWH is the guarantor of this work and, as such, had full access to all the data in the study and takes responsibility for the integrity and the accuracy of the data.

Funding Open Access funding enabled and organized by Projekt DEAL.. Open Access funding enabled and organized by Projekt DEAL.

\section{Compliance with ethical standards}

Conflict of Interests The authors declare that they have no conflict of interests.

Ethical Statement The registry was conducted in accordance with good epidemiology practice and applicable regulatory requirements. The protocol of DPV was approved by the ethics committee of Ulm
University (approval no. 202/09), and data collection was approved by local review board.

Informed consent All patients being enrolled into this registry provided written informed consent.

Open Access This article is licensed under a Creative Commons Attribution 4.0 International License, which permits use, sharing, adaptation, distribution and reproduction in any medium or format, as long as you give appropriate credit to the original author(s) and the source, provide a link to the Creative Commons licence, and indicate if changes were made. The images or other third party material in this article are included in the article's Creative Commons licence, unless indicated otherwise in a credit line to the material. If material is not included in the article's Creative Commons licence and your intended use is not permitted by statutory regulation or exceeds the permitted use, you will need to obtain permission directly from the copyright holder. To view a copy of this licence, visit http://creativecommons.org/licenses/by/4.0/.

\section{References}

1. Husby S, Koletzko S, Korponay-Szabó I et al (2020) European society paediatric gastroenterology, hepatology and nutrition guidelines for diagnosing coeliac disease 2020. J Pediatr Gastroenterol Nutr 70:141-156. https://doi.org/10.1097/MPG.0000000000002497

2. Craig ME, Prinz N, Boyle CT et al (2017) Prevalence of Celiac Disease in 52,721 Youth With Type 1 Diabetes: International Comparison Across Three Continents. Diabetes Care 40:10341040. https://doi.org/10.2337/dc16-2508

3. Smart CE, Annan F, Higgins LA, Jelleryd E, Lopez M, Acerini CL (2018) ISPAD clinical practice consensus guidelines 2018: nutritional management in children and adolescents with diabetes. Pediatr Diabetes 19:136-154. https://doi.org/10.1111/pedi.12738

4. Catassi C, Gatti S, Fasano A (2014) The new epidemiology of celiac disease. J. Pediatr. Gastroenterol. Nutr. 59:7. https://doi. org/10.1097/01.mpg.0000450393.23156.59

5. Losowsky MS (2008) A history of coeliac disease. Dig Dis 26:112-120. https://doi.org/10.1159/000116768

6. Daynes G (1956) Bread and tears; naughtiness, depression and fits due to wheat sensitivity. Proc R Soc Med 49:391-394

7. Keller W, Wiskott A, Beckmann R (1977) Lehrbuch der Kinderheilkunde. 4., neubearb. Aufl., Thieme, Stuttgart

8. Rubio-Tapia A, Murray JA (2019) Updated guidelines by the European society for the study of coeliac disease. United Eur Gastroenterol J 7:581-582. https://doi.org/10.1177/2050640619849370

9. Popp A, Kivelä L, Fuchs V, Kurppa K (2019) Diagnosing celiac disease: towards wide-scale screening and serology-based criteria? Gastroenterol Res Pract 2019:2916024. https://doi. org/10.1155/2019/2916024

10. Uygur-Bayramicli O, Ozel AM (2011) Celiac disease is associated with neurological syndromes. Dig Dis Sci 56:1587-1588. https://doi.org/10.1007/s10620-011-1663-5

11. Casella G, Bordo BM, Schalling R et al (2016) Neurological disorders and celiac disease. Min Gastroenterol Dietol 62:197-206

12. Zylberberg HM, Demmer RT, Murray JA, Green PHR, Lebwohl B (2017) Depression and insomnia among individuals with celiac disease or on a gluten-free diet in the USA: results from a national survey. Eur J Gastroenterol Hepatol 29:1091-1096. https://doi.org/10.1097/MEG.0000000000000932

13. Campagna G, Pesce M, Tatangelo R, Rizzuto A, La Fratta I, Grilli A (2017) The progression of coeliac disease: its neurological and psychiatric implications. Nutr Res Rev 30:25-35. https://doi.org/10.1017/S0954422416000214 
14. Hu WT, Murray JA, Greenaway MC, Parisi JE, Josephs KA (2006) Cognitive impairment and celiac disease. Arch Neurol 63:1440-1446. https://doi.org/10.1001/archneur.63.10.1440

15. Khizroeva J, Nalli C, Bitsadze V et al (2019) Infertility in women with systemic autoimmune diseases. Best Pract Res Clin Endocrinol Metab. https://doi.org/10.1016/j.beem.2019.101369

16. Clappison E, Hadjivassiliou M, Zis P (2020) psychiatric manifestations of coeliac disease, a systematic review and metaanalysis. Nutrients. https://doi.org/10.3390/nu12010142

17. Croall ID, Sanders DS, Hadjivassiliou M, Hoggard N (2020) Cognitive deficit and white matter changes in persons with celiac disease: a population-based study. Gastroenterology. https ://doi.org/10.1053/j.gastro.2020.02.028

18. Mahmud FH, Elbarbary NS, Fröhlich-Reiterer E et al (2018) ISPAD clinical practice consensus guidelines 2018: other complications and associated conditions in children and adolescents with type 1 diabetes. Pediatr Diabetes 19(Suppl 27):275-286. https://doi.org/10.1111/pedi.12740

19. Johnson K (2007) Asymptomatic celiac: does treatment help or hurt? Int Med News 40:46. https://doi.org/10.1016/S1097 -8690(07)70366-9

20. Volta U, Caio G, Manfredini R, De Giorgio R (2018) Detection of asymptomatic celiac disease in two siblings from a mother with nonceliac gluten sensitivity. Gastroenterol Hepatol Bed Bench 11:269-272

21. Liu E, Lee H, Aronsson CA (2014) Risk of pediatric celiac disease according to HLA haplotype and country. N Engl J Med 371:42-49. https://doi.org/10.1056/NEJMoa1313977

22. Depression and Other Common Mental Disorders: Global Health Estimates. Geneva: World HealthOrganization (2017), Licence: CC BY-NC-SA 3.0 IGO

23. Delamater AM, de Wit M, McDarby V et al (2018) ISPAD clinical practice consensus guidelines 2018: psychological care of children and adolescents with type 1 diabetes. Pediatr Diabetes 19:237-249. https://doi.org/10.1111/pedi.12736

24. Plener PL, Molz E, Berger G et al (2015) Depression, metabolic control, and antidepressant medication in young patients with type 1 diabetes. Pediatr Diabetes 16:58-66. https://doi.org/10.1111/pedi.12130

25. Buchberger B, Huppertz H, Krabbe L, Lux B, Mattivi JT, Siafarikas A (2016) Symptoms of depression and anxiety in youth with type 1 diabetes: a systematic review and meta-analysis. Psychoneuroendocrinology 70:70-84. https://doi.org/10.1016/j.psyneuen.2016.04.019

26. Prinz N, Bächle C, Becker M et al (2016) Insulin pumps in type 1 diabetes with mental disorders: real-life clinical data indicate discrepancies to recommendations. Diabetes Technol Ther 18:34-38. https://doi.org/10.1089/dia.2015.0180

27. Wabitsch M, Kunze D (2015) Konsensbasierte (S2) Leitlinie zur Diagnostik, Therapie und Prävention von Übergewicht und Adipositas im Kindes- und Jugendalter, Version 15.10.2015. https://www.a-g-a.de

28. Slim M, Rico-Villademoros F, Calandre EP (2018) Psychiatric comorbidity in children and adults with gluten-related disorders: a narrative review. Nutrients. https://doi.org/10.3390/nu10070875

29. Okan S, Cagliyan Turk A, Sivgın H, Ozsoy F, Okan F (2019) Association of ferritin levels with depression, anxiety, sleep quality, and physical functioning in patients with fibromyalgia syndrome: a cross-sectional study. Croat Med J 60:515-520

30. Pino J, da Luz MH, Antunes HK, Giampá SQ, Martins VR, Lee KS (2017) Iron-restricted diet affects brain ferritin levels, dopamine metabolism and cellular prion protein in a region-specific manner. Front Mol Neurosci 10:145. https://doi.org/10.3389/ fnmol.2017.00145

31. Holmes GK (1996) Non-malignant complications of coeliac disease. Acta Paediatr Suppl 412:68-75. https://doi. org/10.1111/j.1651-2227.1996.tb14257.x

32. Fabiani E, Catassi C, Villari A et al (1996) Dietary compliance in screening-detected coeliac disease adolescents. Acta Paediatr Suppl 412:65-67. https://doi.org/10.1111/j.1651-2227.1996.tb14256.x
33. Sentenac M, Gavin A, Arnaud C, Molcho M, Godeau E, Nic Gabhainn S (2011) Victims of bullying among students with a disability or chronic illness and their peers: a cross-national study between Ireland and France. J Adolesc Health 48:461-466. https ://doi.org/10.1016/j.jadohealth.2010.07.031

34. Sentenac M, Gavin A, Gabhainn SN et al (2013) Peer victimization and subjective health among students reporting disability or chronic illness in 11 Western countries. Eur J Public Health 23(3):421-426. https://doi.org/10.1093/eurpub/cks073

35. Coburn S, Rose M, Sady M et al (2020) Mental health disorders and psychosocial distress in pediatric celiac disease. J Pediat Gastroenterol Nutr 70(5):608-614. https://doi.org/10.1097/ MPG.0000000000002605

36. Mahmud FH, De Melo EN, Noordin K et al (2015) The Celiac disease and diabetes-dietary intervention and evaluation trial (cddiet) protocol: a randomised controlled study to evaluate treatment of asymptomatic coeliac disease in type 1 diabetes. BMJ Open 5:e008097. https://doi.org/10.1136/bmjopen-2015-008097

37. Goddard CJR, Gillett HR (2006) Complications of coeliac disease: are all patients at risk? Postgrad Med J 82:705-712. https://doi. org/10.1136/pgmj.2006.048876

38. Niland B, Cash BD (2018) Health benefits and adverse effects of a gluten-free diet in non-celiac disease patients. Gastroenterol Hepatol 14:82-91

39. Scheuing N, Bartus B, Berger G et al (2014) Clinical characteristics and outcome of 467 patients with a clinically recognized eating disorder identified among 52,215 patients with type 1 diabetes: a multicenter german/austrian study. Diabetes Care 37:1581-1589. https://doi.org/10.2337/dc13-2156

40. Forchielli ML, Diani L, Labriola F et al (2020) Gluten deprivation: what nutritional changes are found during the first year in newly diagnosed coeliac children? Nutrients 12(1):60. https://doi. org/10.3390/nu12010060

41. Amirikian K, Sansotta N, Guandalini S, Jericho H (2019) Effects of the gluten-free diet on body mass indexes in pediatric celiac patients. J Pediatr Gastroenterol Nutr 68:360-363. https://doi. org/10.1097/MPG.0000000000002190

42. Roy T, Lloyd CE (2012) Epidemiology of depression and diabetes: a systematic review. J Affect Disord 142:8. https://doi. org/10.1016/S0165-0327(12)70004-6

43. Charles J, Fazeli M (2017) Depression in children. Aust Fam Physician 46:901-907

44. Ghaziuddin M, Ghaziuddin N, Greden J (2002) Depression in persons with autism: implications for research and clinical care. J Autism Dev Disord 32:299-306. https://doi.org/10.1023/a:1016330802348

45. Pham-Short A, Donaghue KC, Ambler G, Phelan H, Twigg S, Craig ME (2015) Screening for celiac disease in type 1 diabetes: a systematic review. Pediatrics 136:170. https://doi.org/10.1542/ peds.2014-2883

46. Barker JM (2006) Clinical review: type 1 diabetes-associated autoimmunity: natural history, genetic associations, and screening. J Clin Endocrinol Metab 91:1210-1217. https://doi.org/10.1210/ jc.2005-1679

47. Fairweather D, Rose NR (2004) Women and autoimmune diseases. Emerg Infect Dis 10:2005-2011. https://doi.org/10.3201/ eid1011.040367

48. Guedes NG, Silva LAD, Bessa CC, Santos JCD, Silva VMD, Lopes MVDO (2020) Anxiety and depression: a study of psychoaffective, family-related, and daily-life factors in celiac individuals. Revista Brasileira de Enfermagem 73:e20200086. https ://doi.org/10.1590/0034-7167-2020-0086

Publisher's Note Springer Nature remains neutral with regard to jurisdictional claims in published maps and institutional affiliations. 


\section{Affiliations}

\section{Sascha René Tittel ${ }^{1,2}$ (D) Désirée Dunstheimer ${ }^{3} \cdot$ Dörte Hilgard $^{4} \cdot$ Burkhild Knauth $^{5}$. Elke Fröhlich-Reiterer ${ }^{6}$. Angela Galler ${ }^{7}$. Michael Wurm ${ }^{8} \cdot$ Reinhard Walter Holl ${ }^{1,2} \cdot$ For the DPV Initiative}

Désirée Dunstheimer

Desiree.Dunstheimer@uk-augsburg.de

Dörte Hilgard

doerte.hilgard@t-online.de

Burkhild Knauth

burkhild.knauth@cjd.de

Elke Fröhlich-Reiterer

elke.froehlich-reiterer@medunigraz.at

Angela Galler

angela.galler@charite.de

Michael Wurm

michael.wurm@barmherzige-regensburg.de

Reinhard Walter Holl

reinhard.holl@uni-ulm.de

1 Institute for Epidemiology and Medical Biometry, ZIBMT,

Ulm University, Albert-Einstein-Allee 41, 89081 Ulm,

Germany
2 German Center for Diabetes Research (DZD), Munich-Neuherberg, Germany

3 Paediatrics and Adolescent Medicine, Medical Faculty University of Augsburg, Augsburg, Germany

4 Department of Pediatrics, Witten, Germany

5 Department of Pediatrics and Adolescent Medicine, CJD Berchtesgaden, Berchtesgaden, Germany

6 Division of General Pediatrics, Department of Paediatrics and Adolescent Medicine, Medical University Graz, Graz, Austria

7 Charité - Universitätsmedizin Berlin, corporate member of Freie Universität Berlin, Humboldt-Universität zu Berlin, and Berlin Institute of Health, Berlin, Germany

8 Clinic St. Hedwig, University Children's Hospital Regensburg (KUNO Clinics), University of Regensburg, Regensburg, Germany 